\title{
Teaching and Learning English in Thailand and the Integration of Conversation Analysis (CA) into the Classroom
}

\author{
Bunthan Teng ${ }^{1} \&$ Kemtong Sinwongsuwat ${ }^{1}$ \\ ${ }^{1}$ Department of Languages and Linguistics, Faculty of Liberal Arts, Prince of Songkla University, Hat Yai, \\ Thailand \\ Correspondence: Dr. Kemtong Sinwongsuwat, Department of Languages and Linguistics, Faculty of Liberal Arts, \\ Prince of Songkla University, Hat Yai, Thailand. E-mail: ksinwong@gmail.com
}

Received: November 14, 2014 Accepted: December 17, 2014 Online Published: February 13, 2015

doi:10.5539/elt.v8n3p13 URL: http://dx.doi.org/10.5539/elt.v8n3p13

\begin{abstract}
This paper provides an overview of English language teaching and learning, specifically as it pertains to teaching English conversational skills in Thailand. The paper examines the shortcomings of the Communicative Language Teaching (CLT) approach, the current dominant pedagogical approach in the nation, and explores how the integration of Conversation Analysis (CA) can potentially address those shortcomings.It is argued that CA can be used as a teaching tool to raise awareness of the mechanisms of conversation, which are potentially critical to a successful interaction, but often go unnoticed by both teachers and learners. This paper also posits that CA can serve as a diagnostic tool for examining talk and identifying problems that can hinder students from achieving targeted communicative teaching and learning goals. It is recommended that English teachers be trained to deploy CA in conjunction with CLT so as to increase students' overall communicative competence.
\end{abstract}

Keywords: applied CA, communicative language teaching (CLT), conversation analysis (CA), English conversation teaching, interactional competence, speaking skills, Thai EFL classroom

\section{Introduction}

Today, English unquestionably serves an increasingly important role not only as a language of wider communication but as a means of social advancement. In Asia this is especially true as every government member of the Association of Southeast Asian Nations (ASEAN), having adopted Englishas a lingua franca (Kirkpatrick, 2012), has increased efforts to improve English language teaching (ELT) in order to prepare their citizens for the upcoming merger of the ASEAN Economic Community (AEC) in 2015. The AEC integration is expected to foster an environment in which human resources, professional qualifications, and English fluency will all be critical for the success of citizens of every member nation. Therefore, the demand for good ELT approaches is crucial.

In Thailand, the teaching of English speaking skills has been deemed by many to be rather ineffective. This has in fact become a hotly debated issue on the Internet (Joe, 2014; Mitchell, 2013). Kongkerd (2013) accepts that current pedagogical approaches to English teaching in Thailand are not able to help learners become competent English users. According to the National Survey of the Ministry of Education, based on the results of tests carried out in 1997 and 1998, Thai learners' English proficiency was unsatisfactory in the four main skills: writing, reading, listening and speaking (Wiriyachitra, as cited in Khamkhien, 2010). Conducting her study on the general English proficiency of ASEAN students by using the TOEFL-equated Chulalongkorn University Test of English Proficiency (CU-TEP) scores, Prapphal (2001) found out that the average English proficiency of Thai students was higher than that of Laotians but still lower than that of students of other ASEAN countries.

Almost ten years later, Thai learners' English proficiency was still unsatisfactorily low compared to that of students in other Southeast Asian countries (Kamkhien, 2010). More recently, another study conducted by an international language training company using data from online English tests revealed that Thais' English proficiency was among the lowest when compared to English learners in other Asian countries (Bruner, Shimray, \& Sinwongsuwat, 2014). Noom-ura (2013), drawing on data from TOEFL Tests (2011-2012), claims that Thai students who have spent twelve years learning English in primary and secondary schools have relatively low English proficiency compared to their ASEAN country counterparts in Indonesia, Malaysia, the Philippines, and Singapore (see also Atagi, 2011). Wiriyachitra (2002) comments that English language teaching in Thailand has 
failed to prepare Thai learners of English for the fast-changing world and that Thailand will lag behind in the competitive world of modern technology, science, business and education. Almost a decade later, Khamkhien (2010) found that this problem continues to persist.

Such dismal assessments lead to doubts about the quality of the approaches to teaching English in Thailand. In an attempt to improve English language instruction, the Thai government instituted a policy to replace traditional teaching methods as found in grammar translation and audio-lingual approaches with those found in the CLT approach. CLT was introduced in Thai EFL contexts in the mid-1980s (Kustati, 2013; Kwangsawad \& Yawongsa, 2009; Saengboon, 2002). With legislative changes leading to the 1999 National Education Act and 2002 Education Curriculum, more communicative learner-centered approaches have been implemented, resulting in a paradigm shift from teacher-to student-centered approaches (Darasawang, 2007).

Given the fact mentioned above that CLT appears to continuously fail to equip Thai learners with adequate interactive competence, its applicationin the country merits review. As suggested by Islam and Bari (2012), despite its popularity, the CLT approach should be investigated to find out whether there is a mismatch between theory and practice. In fact, Aliakbari and Jamalvani (2010) also inferred that the failure of CLT in practice may be the reason for the introduction of task-based language teaching (TBLT). Along similar lines, while embracing the goal of improving CLT application in Thai ELT, this paper proposes that CA, a sociological approach to studying everyday conversation, in conjunction with aspects of CLT, can be used to produce better competent speakers of English. It is particularly argued that CA can be employed to both enhance learners' conversational abilities and serve as a diagnostic tool to pinpoint communication challenges encountered by students and teachers during an interactionin a Thai EFL classroom (cf. Martin, 2000).

\section{CLT and Its Implementation Problems in Thailand's ELT}

Methitam (2009) reported that CLT is currently widely adopted in Thai ELT, and to insure its implementation, the Thai Ministry of Education (MOE) trained EFL teachers through various professional development programs such as the Project for Improving Secondary English Teachers (PISET), and the Key Personnel Project. While CLT appears to be the most preferred teaching approach, educators and language teachers have also tried other teaching approaches including task-based instruction and content-based instruction in conjunction with CLT (Khamkhien, 2010). However, despite being highly preferred, the implementation of CLT as the dominant pedagogy has not netted the fluency outcome hoped for as Thai students' English proficiency still remains low. Scholars posit that this continues to be the case as Thai teachers are still struggling with executing CLT (Kustati, 2013); some of the struggle persists for an array of reasons:

1) A lack of sustained professional development and teacher fluency

Wanchai (2012) put it that Thai teachers' insufficient English proficiency is a constraint and they failed to implement CLT effectively. Teachers who teach English in Thailand are mostly nonnative speakers and too often are low proficient in oral English; therefore, they mostly use Thai as the medium of instruction (Bruner et al, 2014; Khamkhien, 2010).

2) Insufficient time to implement CLT activities

English classes in Thailand are generally organized into 50-minute sessions (Darasawang, 2007). Islam and Bari (2012) revealed instructors' frustrations at not being able to implement all the CLT activities planned since they often take considerable time.

3) Learners' preference for accuracy over fluency

Saengboon (as cited in Khamkhien, 2010) observed that Thai teachers often put emphasis on grammatical competence, drill-based activities and rote memorization of isolated sentences. Moreover, Islam and Bari (2012) revealed that Thai students focused mainly on their grades and examinations.

4) Large class size

The average Thai English class has more than 40 students often with varying levels of fluency (Dhanasobhon, 2006). As a result, teachers are facing difficulty in preparing activities and materials to suit different student needs. Additionally, classroom management issues in such large classes often lead to time spent off task, further shortening the already limited contact time (Islam \& Bari, 2012).

5) Students being uncooperative and uncomfortable with CLT

Thai students have expressed uncomfortable feelings with CLT and some have even cited a conflict between Thai culture and the teaching approach. Wangkijchinda (as cited in Kongkerd, 2013) argued that the CLT approach might not fit Thai EFL context as Thai students, because of cultural values, are reticent to question 
their seniors. This was confirmed in Saengboon (2002) that Thais are not supposed to challenge and confront teachers or superiors. Therefore, Thai students, it is asserted, often assume a more passive role in the classroom in which a transmission model of pedagogy is generally employed. Others have argued that CLT is appropriate for students embracing individualism but not for those favoring collectivismwhich is highly prevalent in many Asian contexts such as Thailand (Cook, 2001; Ellis, 1996; Hofstede, 1980; Jeon, 2009; Lochland, 2013; Tan, 2005).

\section{6) Misconception about CLT application}

According to Methitham and Chamcharatsri (2011), a heavy burden is imposed on the learners as native-speaker (NS) norms are prioritized as the only way to become competent English speakers, and Thai teachers' and learners' cultural background and local literacies are often neglected in the learning process. Jenkins (as cited in Lochland, 2013) criticized CLT for regarding NS norms as the default model to follow, arguing that EFL learners have little chance to speak with NSs but are more likely to communicate with their fellow nonnative speakers (NNS) (see also Kramsch, 2014; Saengboon, 2002).

While the aforementioned are indeed formidable challenges, many of these challenges can be mitigated through ongoing professional development in the areas of pedagogy and English fluency. However, addressing these challenges, while certainly important, is not within the scope of this paper. Instead, this paper focuses on fundamental and critical weaknesses of CLT within the Thai context and proposes that these weaknesses can be addressed by infusing CA into the CLT classroom.

\section{The Merger of CA and CLT}

Despite the aforesaid problems in CLT implementation, CLT is a corrective approach to the drawbacks of traditional methods. According to Brown (2001), CLT provides students with tools for developing language performance for real-life communication and language techniques are tailored to get students involved in the pragmatic, authentic and functional use of language for meaningful purposes. Moreover, students are given opportunities to devote attention to their learning process and encouraged to build meaning by assuming roles as negotiators and interactants via authentic linguistic communication with others. Teachers assume the roles of facilitators and guides. According to Richards (2006), CLT activities encourage students to personalize their own learning as well as to apply what they have learned to their own lives. Kirkpatrick and Ghaemi (2011) point out that CLT principles let students employ the target language in meaningful contexts, thus bringing the real world into the classroom. Finocchiaro and Brumfit (as cited in Brown, 2001) maintain, "Communicative competence is the desired goal, fluency and acceptable language are the primary goal; accuracy is judged not in the abstract but in context" (p. 45). Richards (2006) posits that CLT develops four skills: reading, speaking, listening and writing from the beginning and that both fluency and accuracy are developed as students' errors are tolerated.

However, critics of CLT argue that communicative competence through the CLT approach is not sufficient to help students effectively communicate in various intercultural settings within EFL contexts. They assert that there is a lack of attention to learning context. Bax (2003) argues that CLT has not always taken into account the context in which it is employed and which is a key determiner of the learners' failure or success. He states that in language teaching the first priority is the learning context, including students' needs, wants and learning preferences; the coursebooks; local conditions; and the national, school and classroom cultures. He recommended that based on context analysis, varied students' needs will be probably met by a more eclectic approach, not with CLT alone. Le Ha and Chowdhury (as cited in Lochland, 2013) stress that CLT cannot cover the complex educational needs and cultures of students in particular settings. Lochland (2013) posits that CLT, a so called one-method-fits-all approach to ELT, does not apparently work in all English language classrooms. This is in line with Nunan's (as cited in Jeon, 2009) argument that it appears true that no one method fits all because different contexts require different methods (see also Lin, 2009).

Others have argued that interactional competence (IC) is critical and it is a missing component in CLT. According to Sun (2014), "Interactional competence differs from communicative competence in its focus on interactions from a constructivist approach to the development of spoken English-they believe that conversational competence is co-constructed by speakers involved in the conversation. Thus, it calls for greater attention to interactions between learners (p. 5). Wong and Waring (2010) mentioned that Celce-Murcia's (2007) revised model of communicative competence often overlooks the role of IC. The latter is defined as the capability to employ different interactional resources, such as turn-taking devices and repair mechanisms in dealing with problems in speaking, hearing, and understanding. This concept is well explained in Barraja-Rohan (2011), Kasper (2006), Kramsch (1986) and Young (1999).

He and Young (1998) suggest IC as a replacement for communicative competence, as they are convinced that 
"individuals do not acquire a general, practice-independent competence; rather they acquire a practice-specific interactional competence by participating with more experienced others in specific interactive practices" (p. 7). CLT has not taken L2 classroom interaction into account from any communication or sociolinguistic theory but from a single, invariant pedagogical concept (Seedhouse, 2004).

Others have charged that CLT does not provide a firm direction in teaching conversation and that features of everyday conversations are often neglected. In the preface of Barraja-Rohan and Pritchard's (1997) Beyond talk, Dr. Anthony J. Liddicoat states that "even though language teaching has aimed to be communicative and has focused on oral language use, features of everyday conversation have often been ignored or undervalued in language textbooks" (p. 1) (see also Wong \& Waring, 2010). Barraja-Rohan (1997) suggests that in the current language teaching approach, teachers are not given a firm direction when learning to teach conversation. They may feel perplexed and simply depend on various communicative activities such as games, role-plays, their own imagination and a selection of predesigned activities from different course books. Therefore, the methods used to teach conversation are often unsatisfactory because conversation is very complex; course books, too, often do not offer explicit attention to sociocultural norms or interaction norms that appear in everyday conversation. Wong and Waring (2010) suggest that language teachers are not given firm direction on how spoken language works and their teaching of conversation often does not reflect the way people talk in the real world.

\subsection{CA and CLT}

The current paper argues that the aforementioned problems can be addressed using CA. According to Seedhouse (2004), scholars in social science recognize the importance of a classroom as the social context in which most students learn L2 and L2 classroom talk offers a crucial context for language learning because "Learning is situated; learning is social; and knowledge is located in communities of practice and that learning not only takes place in the social world, it also constitutes that world" (Brouwer \& Wagner, p. 33 as cited in Seedhouse, 2007). He (as cited in Kasper, 2006) posits that CA contributions to SLA primarily lie in its ability to specify how classroom activities are interactionally achieved and what opportunities for L2 learning these interactional environments afford. Therefore, in English language teaching, the most important thing to pay attention to "is to identify the core institutional goal, which is that the teacher will teach the learners L2. This core goal remains the same wherever the L2 lesson takes place and whatever pedagogical framework the teacher is working in" (Seedhouse, 2004, pp. 183-184). Seedhousefurther argues that the goal offers three universal properties in all second language classroom interaction:

1) Language is both the medium and object of instruction.

2) There is a reflexive relationship between pedagogy and interaction in the classroom. The organization of the interaction will vary depending on the pedagogical focus.

3) What the students say and respond in the L2 classroom provide teachers with critical linguistic forms and patterns of interaction for feedback and evaluation (see Van Lier, 1988a).

To effectively engage in intercultural interaction, participants have to understand the inherent norms of interaction or sociocultural norms (Barraja-Rohan, 1997), the ways in which norms of interaction change based on situational factors and the ways in which speakers from other language backgrounds might have different expectations of language usage and behavior (Bowe \& Martin, 2007). Moreover, Brouwer and Wagner (as cited in Seedhouse, 2007) suggest that L2 teaching shift from the "conception of language in terms of individual cognition and an input-output approach to acquisition of discrete linguistic (typically syntactic or lexical) items" to "the development of interactional skills and resources and conceptualizing language learning as a social process" (p. 11). As Barraja-Rohan (1997) argues, focusing on written-grammar accuracy overlooks the fact that interactants look for meaning rather than just grammatical accuracy. CA discloses that native speakers also make a lot of linguistic mistakes in speaking but they manage to keep conversation going; if there are any problems with their understanding, they use repair mechanisms to solve the problems to avoid communication breakdowns. CA will make teachers become aware of interactional practices (IP), which are the systematic verbal and nonverbal methods interactants employ to participate in social interaction and key components of IC (Wong \& Waring, 2010). Barraja-Rohan (1997) maintains that to operate effectively in society a thorough understanding of the norms of interaction is essential since these cultural specific norms operate at every moment in an interaction.

Wong and Waring accordingly suggest that language learners should develop IC in conjunction with other components of communicative competence. Teachers, on the other hand, should understand the genuine nature of talk-in-interactionto be able to teach it more efficaciously. They additionally argue that CA is a unique and innovative tool to achieve the conversation teaching goal since it not only manages to capture all the features of 
conversation, but serves as an effective tool for uncovering and teaching these sociocultural norms (Barraja-Rohan, 1997, 2011; Wong \& Waring, 2010).

CA, which, as will be argued, can be used both as a teaching and diagnostic research tool, has yet to be applied in an English teaching and learning setting especially in Thailand. In fact, none of the research papers related to speaking skill teaching (out of 99) listed in the Thai Library Integrated System (ThaiLIS) (2014) adopted CA or showed relevancy between CA and Thai English classes. Therefore, it is worth briefly introducing the basics of CA, making the features of conversation explicit to wider untrained eyes of audience in ELT.

\section{Introduction to $\mathrm{CA}$}

$\mathrm{CA}$ is an approach in which language and social interaction are analyzed. Originating from the work of sociologists Harvey Sacks, Emanuel Schegloff and Gail Jefferson in the 1960s (Wong \& Waring, 2010), CA is a tool used to examine and analyze naturally occurring talk through recording and transcribing human talk-in-interaction (Seedhouse, 2004; Sinwongsuwat, 2007). CA, however, does not put emphasis on building structural models of such talks but rather on the sole investigation of the performance of participants in interaction and of patterns occurring over a wide range of natural spoken interaction (McCarthy, 1991).

\subsection{Principles of $C A$}

CA pays unique attention to human actions accomplished via talk. CA analysts attempt to determine how participants analyze and interpret one another's talk in interaction and generate a shared understanding of the interaction (Seedhouse, 2004). They try to step inside the shoes of interactants to make sense of their talk and actions (Wong \& Waring, 2010). The aim is to "discover how participants understand and respond to one another in their turns at talk, with a central focus being on how sequences of actions are generated" (Hutchby \& Wooffitt, 1998, p. 14). CA thus focuses on three major types of data: 1) naturally occurring data taken from the actual occurrences of talk not from manipulation, 2) transcribed data using a fine-grained transcription system and 3) analyzed data from an emic perspective which accounts for interlocutors' language in social interaction (Wong \& Waring, 2010).

\subsection{Structures of Conversation}

The following structures of interactional organization are unveiled via CA, namely turn taking, sequential organization, adjacency pairs, preference organization, and repairs.

\section{1) Turn-taking}

Turn-taking is a central concept to CA and its role in conversation is at the heart of CA. CA deals with how turn-taking is organized, how participants accomplish orderly turn-taking in talk and what systematic resources are employed (Hutchby \& Wooffitt, 1998). According to Sacks (as cited in Wong \& Waring, 2010), turn-taking is comprised of two important components: turn-constructional component and turn-allocational components. The turn-constructional component consists of the building blocks of turns called turn-constructional units (TCUs), each of which has transitional relevance place (TRP), which makes speaker transition relevant (Hutchby \& Wooffitt, 1998; Seedhouse, 2004).

Trudgill (1983) states that in a conversation, interactants speak one at a time alternatively taking turns, providing the turn taker not only the right but also the obligation to speak. The obligation that a speaker has reflects a selectional or allocational property of the turn-taking system. Once the turn is underway, a TRP where speaker selection or turn allocation is accomplished can be projected and a different speaker has an obligation to take his/her turn. However, if no speaker selection takes place, the same speaker has the right to continue. Turn-taking is therefore a pivotal component of IP, which can vary from culture to culture, and comprehending these differences enables students to avert unintentional cross-cultural mistakes (Wong \& Waring, 2010).

\section{2) Adjacency pairs (AP)}

Utterances in conversation conventionally come in pairs, called adjacency pairs, for instance, question and answer, greeting and greeting, invitation and acceptance/declination (Hutchby \& Wooffitt, 1998). Upon the production of the first part of the pair (e.g., question), the second part of the pair (e.g., answer) becomes conditionally relevant (Seedhouse, 2004). However, if the second pair-part is not immediately produced, it may remain relevant and accountable and appear later, or its absence needs to be accounted for.

\section{3) Sequential organization}

It is argued that turns at talk are not serially but sequentially ordered and one aim of CA is to explicate this sequential order. Levinson (1983) illustrates that a question may not be followed by an answer immediately. The second pair part of an adjacency pair can be postponed by an insertion sequence as shown in lines 2-3 in the 
example below:

1 A: Can I have a bottle of Mich?

2 B: Are you over twenty-one?

3 A: No.

4 B: No.

(Levinson, 1983, p. 304)

The inserted sequence serves as a contingency for the production of the response to the first pair turn in line 1 . The latter is delayed until more relevant information about the age of A is received. Speaker A also orients to the postponement by answering the inserted question in line 3. Once the insertion sequence is completed, B demonstrates that he is still orienting to the main sequence by giving the relevant second part in line 4 . This conversation confirms that the interactants demonstrate their understanding of each utterance aim and respond accordingly in a sequential not serial order.

4) Preference organization

Preference organization is another notion introduced by CA and it concerns structural features of turn design which participants in talk-in-interaction use to infer certain kinds of action (Hutchby \& Wooffitt, 1998). Preference structure does not refer to the preference of doing something, but is related to the issues of affiliation and disaffiliation, seeing, noticeability, accountability and sanctionability regarding social actions (Boyle as cited in Seedhouse, 2004). According to Cook (1989), there is generally supposed to be a choice of two possible answers to any first pair-part, but if there is the absence of an answer, it signals rudeness, inaudibility or a lack of attention. The most frequently recurring answer is termed a preferred response and the less common one a dispreferred response. For instance, in the case of an invitation, acceptances are preferred and declinations dispreferred. Preferred responses are usually delivered without hesitation or delay, whereas dispreferred actions are normally delayed and prefaced with discourse markers like well, $u h, \mathrm{~mm}$ and followed by explanations (Pomerantz as cited in Seedhouse, 2004). The absence of a preferred response is noticeable and needs to be accounted for by relevant parties, or it could be sanctioned by the first pair-part speaker.

5) Repair

During an interaction, participants may encounter problems and the problems are usually fixed to avoid misunderstanding or communication breakdowns via repair mechanisms. Problem-preempting or solving mechanisms, or repair, can be performed in one of the following fashions: 1) self-initiated self-repair; 2) other initiated self-repair; 3) self-initiated other repair; 4) other initiated other-repair. Hutchby and Wooffitt (1998) point out that in self-initiated self-repair, a speaker of the trouble source fixes the problem on their own. For other-initiated self-repair, the speaker of the trouble source is prompted to execute the repair by the other speaker. For self-initiated other-repair, the problem is corrected by the recipient, whereas in the other-initiated other-repair, the recipient of the trouble source turn both initiates and executes the repair.

\subsection{The Potential of CA Application in Thai ELT}

Unlike a typical Thai EFL classroom, students in a CA-informed class will be introduced to interactional resources such as turn-taking and repair mechanisms along with sociocultural norms of interaction (see Barraja-Rohan, 1997, 2011; Barraja-Rohan \& Pritchard, 1997). They will be made aware of such templates for norms enforcement and action interpretation as adjacency-pairs sequences (see also Seedhouse, 2004). Through these resources, CA will also enable teachers to assess students' understanding of sociocultural norms when performing various actions within interaction (Fujii, 2012). Additionally, according to Wu (2013), CA may be used to enhance sociolinguistic competence by acquainting learners with transcriptions of NSs' and NNSs' spoken data, discourse competence by investigating conversational sequences, linguistic competence by examining aspects of conversation organization and strategic competence by investigating how people take, retain, and deliver their turns, as well as open and close a conversation. More important, the CA-oriented pedagogical approach emphasizes using real life language in authentic social interactions (Barraja-Rohan, 1997, 2011), undermining the pervasive use of such unnatural conversation as scripted role-play in Thai conversation classrooms.

Given the insights into mechanisms or norms of conversation offered, CA can potentially serve both as a teaching and a diagnostic tool in a classroom (Fujii, 2012; Martin, 2000). As a teaching tool, CA can demonstrate to both NSs and language learners alike how interlocutors of any particular community interact with one another and make sense of one another's interactional contributions (Barraja-Rohan, 2011). CA has been used to boost 
interaction-based learning (Martin, 2000), which views language learning as occurring through interactions between teachers and learners. Stated by Laurillard (as cited in Ngaleka \& Uys, 2013), for learning to take place, teachers and students must interact with each other in the learning process. Mitchell and Myles (as cited in Barraja-Rohan, 2011) posit that the revelation of the mechanisms which L2 participants use in conversation can facilitate conversation learning since students are able to see the discrepancies and similarities between $\mathrm{L} 1$ and L2. Gardner (2008) argues that conducting CA on L2 talk is the same as using CA on L1 talk. CA traces what is happening, and how interactants are co-constructing sequences of actions. Fujii (2012) additionally argues that students' sociocultural awareness can really be raised if they are engaged in analyzing the sequential organization of conversation and they can anticipate, interpret and get involved in cross-cultural practices via CA.

Barraja-Rohan (2011) conducted an experimental study using a CA-informed pedagogical approach to teach two groups of students in Australia. Group 1 comprised 20 adult migrants, aged from early 20 to over 60, with lower intermediate level. Since the CA-oriented pedagogical approach proved successful, the teacher- researcher set up an elective conversation class for group 2, consisting of 10 international students and some migrants, from late teens to early twenties, with intermediate language level. In the study of 12-week course with two hours per week, the teacher-researcher taught the students CA concepts with materials including audio or videotaped naturally occurring conversations conducted by NSs and a CA-based course book, Beyond Talk (Barraja-Rohan \& Pritchard, 1997). At the end of the course, an evaluation questionnaire was launched to find out the participants'reaction to the new approach. The findings showed that both groups improved their listening and speaking skills and increased their confidence in speaking. The participants reported that CA methodology helped them to apply the concepts in their interactions with other learners and NSs, which facilitated their interactions. They became more effective conversationalists while acquiring different aspects of L2 IC. However, according to the analyses of the students' conversations, the researcher suggested that there was a need to teach a number of interactional features and concepts unveiled by CA so that the students would be able to employ them.

Fujii (2012) conducted a study on 100 Japanese non-English major undergraduates at a private university in Japan, using online video resources to teach the basic concepts of CA and a post-experiment questionnaire to find out students' reaction to CA. The results of the study confirmed that the participants developed a heightened awareness and understanding of the actual differences between contrived dialogues in textbooks and naturally occurring conversations in actual language situations. Moreover, they appreciated the opportunity to examine the intricacies of unscripted English conversations usually excluded from the typical ESL classroom and commented that CA was useful for understanding language-specific ways of talking and helped learners to learn the target language more easily, as well as identify and understand the rules of language they had never noticed before. The majority of the participants responded positively and maintained that CA was helpful for understanding the key principles of spontaneous conversation and was convinced that repeated listening to naturally occurring conversation could be helpful in improving their own listening comprehension skills.

However, when asked about the unnaturalness of conversational scripts in textbooks, the participants responded differently; $30 \%$ had never given it serious thought, and lacking English competence, $91 \%$ felt that conversation is a complex process. In addition, the researcher suggested that learners be taught cross-cultural communication skills since they experienced some resistance to conforming to NS' norms and some of them reacted negatively to these norms. CA was employed in Packett's (as cited in Mori, 2007) study to introduce the case of English for specific purposes (ESP) courses designed for L2 learners trained in the field of journalism. Packett used CA techniques and got the learners to inductively discover how journalistic broadcast interviewing is constructed and what consequences could occur from undertaking or not understanding a particular action in the course of interaction. It was shown that CA can help to develop future journalists as reflective practitioners.

Moreover, apart from providing a theoretical framework and a methodology to teach interactional competence, $\mathrm{CA}$ can be used to diagnose and show communication problems learners experience during an interaction. In their studies, both Barraja-Rohan (2011) and Fujii (2012) also reported that CA was a powerful tool to analyze L2 interaction as well as to identify causes of interactional problems. Bowles (2006) employed CA techniques to examine how the sequential structure and pragmatic functions of telephone call openings were manifested in pre-sequences produced by English NSs and NNSs. Two corpora of service telephone calls to English bookshops between NS-NS and NSS-NS were compared. The callers were at the age ranging from 18 to 64 and of mixed sex and social class. The results showed that NNSs performed less satisfactorily than NSs with regard to concepts identified by CA. It was suggested that not only a description of the sequencing conventions of different languages and the kind of language used to implement them, but also a method for identifying, explaining and practicing sequencing difficulties were needed to help NNSs become better competent speakers. 
Moreover, it was argued that ESP and CA can be brought into closer alignment and CA data can be aligned with language for specific purposes not only in the area of service talk but also other types of institutional talk.

Clifton (2011) conducted a CA-integrated study with pre-service students in a multilingual professional communication program at Antwerp University, Belgium. The students were NNS and all had an excellent level of English. In this study, the researcher attempted to integrate CA's emphasis on the natural observation of talk with reflective practice. The results reaffirmed that students learning ESP can really benefit from doing CA and students were able to analyze transcripts of spoken interactions using CA, reflect upon their practice, and improve their interactional skills. However, according to the students' assessment of the course, the students' main complaint was the time spent on acquiring the basics of CA. Similarly, S. Tan and A. Tan (2006) conducted a study using data from an online discussion and a face-to-face interaction. In both data sets, the teachers interacted with a group of students. It was suggested that CA could be used as a tool to analyze interactions between learners and instructors in both environments. By using CA, it was uncovered that the students can be empowered to steer the discussion provided that they possess knowledge-building capacity to engage in meaningful and constructive discourse, allowing the teacher to take a controlled absence by playing a facilitator's role.

Since CA was introduced, it has attracted many researchers and teaching practitioners seeking new ways to help their students become more conversationally proficient. The approach has in fact been making inroads into second or foreign language teaching, and there is a noticeably growing body of research on CA in second language learning and applied linguistics (Barraja-Rohan, 2011; Gardner, 2008; Kasper, 2006, Mori, 2007; Seedhouse, 2004; Sert, 2010; Sert \& Seedhouse, 2011). An increasing number of studies additionally attribute a significant role to CA in teacher education. Huth and Taleghani-Nikazm (2006) argued that CA-based materials can serve as important instructional resources for teaching and raising students' L2 pragmatic awareness. However, the researchers advised that L2 instructors have a good command of basic CA concepts so as to ensure that they could effectively introduce these concepts to students. Having seen the potential of CA, Sert (2010) recommended that CA be integrated into English language teacher education programs in Turkey. Moreover, a number of 'applied CA' studies, or 'CA-like' studies, have also started to emerge, thereby underscoring the merit of applying CA as a teaching and research toolin Thai ELT (see Chotirat, 2011; Makeh \& Singwongsuwat, 2014; Naksevee, 2013; Nookam, 2010; Rodpradit \& Singwongsuwat, 2012; Ussama \& Singwongsuwat, 2014).

\section{Concluding Remarks}

As elucidated in this paper, currently the most preferred approach to teaching English speaking in Thailand and other similar contexts is CLT. The paper argues that this approach can be more efficacious with the integration of aspects of CA. CA can especially serve as an instructional tool for raising learners' awareness of the genuine nature of interactions and enhancing interaction-based learning, as well as provide instructors with a powerful lens for identifying problems within classroom interactions. As the numerous aforementioned studies indicate, a CA-oriented pedagogical approach has proven successful not only in equipping learners with better interactional competence but also in identifying and addressing problems in classroom teaching. With the ASEAN Economic Community (AEC) merger on the horizon and all that is at stake with that merger, it is critical that the shortcomings of the most dominant pedagogical approach, CLT, be addressed. CA can offer complement to CLT that may well provide English learners with a level of communicative competency that will allow them to more effectively operate within the high-stakes AEC community.

\section{Acknowledgements}

The authors would like to express special thanks to Dr. Kathleen Nicoletti for taking her time to review the earlier drafts and giving very helpful comments to improve this manuscript.

\section{References}

Aliakbari, M., \& Jamalvandi, B. (2010). The impact of 'Role Play' on fostering EFL learners' speaking ability: A task-based approach. Pan-Pacific Association of Applied Linguistics, 14(1), 15-29.

Atagi, R. (2011). Secondary Teacher Policy Research in Asia: Second Teachers in Thailand. Bangkok: UNESCO Bangkok, 2011. Retrieved July 10, 2014, from http://www.uis.unesco.org/.../secondary-teacher-policyresearch-asia-thailand-e

Barraja-Rohan, A.-M. (1997). Teaching language, Teaching Culture. Teaching conversation and sociocultural norms using conversation analysis and aspects of pragmatics. Australian review of applied linguistics. Retrieved July 26, 2014, from http://www.academia.edu/1055516/1997

Barraja-Rohan, A.-M. (2011). Using conversational analysis in the second language classroom to teach 
interactional competence. Language Teaching Research, 15(4), 479-507. http://dx.doi.org/10.1177/ 1362168811412878

Barraja-Rohan, A.-M., \& Pritchard, C. R. (1997). Beyond talk. A course in communication \& conversation for intermediate adult learners. Teacher's book. Western Melbourne Institute of TAFE. Melbourne, Australia.

Bax, S. (2003). The end of CLT: A context approach to language teaching. English Language Teaching Journal, 57(3), 278-287.

Bowe, H., \& Martin, K. (2007). Communication across cultures. Mutual understanding in a global world. Cambridge University Press.

Bowles, H. (2006). Bridging the gap between conversation analysis and ESP—An applied study of the opening sequences of NS and NNS service telephone calls. English for Specific Purposes, 25, 332-357. http://dx.doi.org/10.1016/j.esp.2005.03.003

Brown, H. D. (2001). Teaching by principles. An interactive approach to language Pedagogy (2nd ed.). New York. Longman.

Bruner, D. A., Sinwongsuwat, K., \& Shimray, Y. P. (2014). Thai-Serbian A2 university EFL learners' perspectives on learning and teaching oral English communication skills. In P. Subphadoongchone (Ed), The 34th Thailand TESOL International Conference Proceedings 2014 (pp. 13-34). Chiang Mai: TESOL Thailand.

Chotirat, S. (2011). Oral performance in scripted and non-scripted role-play activities: A study of repair organization in English conversation of Thai college students (Unpublished master's thesis.). Prince of Songkla University, Thailand.

Clifton, J. (2011). Combining conversation analysis and reflective practice in the LSP classroom: Putting transcripts of business simulations under the microscope. J. Clifton/ScriptaManent, 6(1-2), 25-34. Retrieved July 18, 2014, from www.sdutsj.edus.si/ScriptaManent/2011_6_1,2/Clifton.pdf

Cook, G. (1989). Discourse. Oxford University Press.

Cook, V. (2001). Second language learning and language teaching (3rd ed.). New York: Arnold.

Darasawang, P. (2007). English language teaching and education in Thailand: A decade of change. In N. D. Prescott (Eds.), English in Southeast Asia: Varieties, literacies and literatures (pp. 187-204). Cambridge Scholars Publishing.

Dhanasobhon, S. (2006). English language teaching dilemma in Thailand. Retrieved July 14, 2014, from http://www.curriculumandinstruction.org/index.php?lay=show\&ac...7

Ellis, G. (1996). How culturally appropriate is the communicative approach? ELT journal, 50(3), 213-218.

Fujii, Y. (2012). Raising awareness of interactional practices in L2 conversations: Insights from conversation analysis. International Journal of Language Studies, 6(3), 99-126.

Gardner, R. (2008). Conversation analysis and orienting to learning. Journal of Applied Linguistics, 5(3), 299-244. http://dx.doi.org/10.1558/japl.v5i2.229

He, A. W., \& Young, R. (1998). Language proficiency interviews: A discourse approach. In R. Young, \& A. W. He (Eds.), Talking and Testing: Discourse approaches to the assessment of oral proficiency (pp. 1-24). Philadelphia: John Benjamins.

Hofstede, G. (1980). Culture's consequences: International differences in work-related values. Newbury Park, CA: Sage.

Hutchby, I., \& Wooffitt, R. (1998). Conversation Analysis. Cambridge. Polity Press.

Huth, T., \& Taleghani-Nikazm, C. (2006). How can insights from conversation analysis be directly applied to teaching L2 pragmatics? Language Teaching Research, 10(1), 53-79.

Islam, M. J., \& Bari, I. S. (2012). Implementation of CLT in Bangladesh and Thailand. Retrieved July 6, 2014, from http://www.academia.edu/.../Implementation_of_CLT_in_Bangladesh_and_Th

Jeon, J. (2009). Key issues in applying the communicative approach in Korea: Follow up after 12 years of implementation. English Teaching, 64(4), 123-150.

Joe, K. (2014). English Language Education in Thailand: Where to go next? Retrieved July 3, 2014, from http://joechou.bloggang.com/ 
Kasper, G. (2006). Beyond repair. Conversation analysis as an approach to SLA. AILA Review, 19, 83-99.

Khamkhien, A. (2010). Teaching English speaking and English speaking tests in the Thai context: A Reflection from Thai Perspective. English Language Teaching, 3(1), 184-190.

Kirkpatrick, A. (2012). Teaching English as a lingua franca in ASEAN: Maintaining linguistic and cultural diversity. Proceeding of the 2012 International Conference on Cultural and Linguistic Diversity in ASSEAN, Suan Dusit Rajabhat Unversity, Bangkok, Thailand, 17-25.

Kirkpatrick, R., \& Ghaemi, H. (2011). Beyond the communicative approach in language teaching. Modern Journal of Language Teaching Methods, 1(3), 143-139.

Kongkerd, W. (2013). Teaching English in the era of English used as a lingua franca in Thailand. Retrieved July 12, 2014, from http://www.bu.ac.th/knowledgecenter/executive_journal/oct_dec.../aw01.pdf

Kramsch, C. (1986). From language proficiency to interactional competence. The Modern Language Journal, 70(4), 366-372.

Kramsch, C. (2014). Teaching foreign languages in an era of globalization: Introduction. The Modern Language Journal, 98(1), 296-311. http://dx.doi.org/10.1111/j.1540-4781.2014.12057.x

Kustati, M. (2013). The shifting paradigms in the implementation of CLT in Southeast Asia countries. Retrieved July 5, 2014, from http://journal.tarbiyahiainib.ac.id/index.php/attalim/article/download/23/31/pdf

Kwangsawad, T., \& Yawongsa, P. (2009). Bridging the gap between CLT and CBI theory and practice. Retrieved July 12, 2014, from http://www.yumpu.com/.../bridging-the-gap-between-clt-and-cbi-theory

Levinson, S. (1983). Pragmatics. Cambridge, England: Cambridge University Press.

Lin, Y. (2009). Culturally responsive communicative teaching (CRCLT): A new alternative for EFL teachers in China and other non-English speaking countries. Canadian and International Education, 38(2), 88-103.

Lochland, P. W. (2013). Moving beyond communicative language teaching: A situated pedagogy for Japanese EFL classrooms. TESOL International Association, 4(2), 261-273.

Makeh, A., \& Singwongsuwat, K. (2014). Improving and retaining oral English performance with scripted role-play: A study of Thai primary school students. In International Proceedings of L-SA Workshops \& Colloquium 2014. Faculty of Liberal Arts, Prince of Songkla University, Hat Yai, Songkla.

Martin, G. S. (2000). Conversation Analysis. Routledge Encyclopedia of Language teaching and learning (pp. 145-148).

McCarthy, M. (1991). Discourse analysis for language teachers. Cambridge University Press.

Methitham, P. (2009). An Exploration of Culturally-based Assumptions Guiding ELT Practice in Thailand, a Non-colonized Nation (Unpublished Dissertation). Indiana University of Pennsylvania, Indiana.

Methitham, P., \& Chamcharatsri, P. B. (2011). Critiquing ELT in Thailand: A reflection from history to practice. Journal of Humanities, Naresuan University, 8(2), 57-68.

Mitchell, T. (2013). Why is English so poor in Thailand? Retrieved August 10, 2014, from http://www.ajarn.com/ajarn-guests/article

Mori, J. (2007). Border crossing? Exploring the intersection of second language acquisition, conversation analysis, and foreign language pedagogy. The Modern Language Journal, 91, 849-862.

Naksevee, N. (2013). Using non-scripted role-play to teach speaking skills: A study of English conversation of Thai college students at YalaRajabhat University (Unpublished master's thesis). Prince of Songkla University, Thailand.

Ngaleka, A., \& Uys, W. (2013). M-learning with whatsapp: A conversation analysis. Proceedings of the International Conference on e-Learning 2013 (pp. 282-291).

Nookam, W. (2010). Thai EFL learners' use of discourse markers in English conversation: A study of business English students at Didyasarin international college (Unpublished master's thesis). Prince of Songkla University, Thailand.

Noom-ura, S. (2013). English-teaching problems in Thailand and Thai Teachers' Professional Development Needs. English Language Teaching, 6(11), 139-147. http://dx.doi.org/10.5539/elt.v6n11p139

Prapphal, K. (2001). English proficiency of Thai Learners and directions of English teaching and learning in Thailand. Retrieved July 4, 2014, from http://pioneer.chula.ac.th/ pkanchan/doc/EnglProfLearnhailand.doc 
Richards, J. C. (2006). Communicative language teaching today. Cambridge University Press.

Rodpradit, S., \& Singwongsuwat, K. (2012). Using scripted and non-scripted role-plays to improve speaking performance of hotel engineering staff. APHEIT Journal, 18(1), 17-25.

Saengboon, S. (2002). Beliefs of Thai EFL teaching about communicative language teaching (Unpublished doctoral dissertation). Indiana University, Bloomington USA.

Seedhouse, P. (2004). The interactional architecture of language classroom: A conversation analysis perspective. University of Michigan. Blackwell.

Seedhouse, P. (2007). Interaction and constructions. In Z. Hua, P. Seedhouse, L. Wei, \& V. Cook (Eds.), Language learning and teaching as social inter-action (pp. 9-21). New York, NY: Palgrave Macmillan.

Sert, O. (2010). A proposal for a CA-integrated English language teacher education program in Turkey. ASEAN ELT JOURNAL, 12(3), 62-97.

Sert, O., \& Seedhouse, P. (2011). Introduction: Conversation analysis in applied linguistics. Novitas-ROYAL (Research on Youth and Language), 5(1), 1-14.

Sinwongsuwat, K. (2007). Conversation analysis (CA): An introduction from a linguist's perspective. School of Language and Communication, 12(12), 38-57.

Sun, D. (2014). From communicative competence to interactional competence: A New Outlook to the Teaching of Spoken English. Journal of Language Teaching and Research, 5(5), 1062-1070.

Tan, M. (2005). CLT-beliefs and practices. Journal of Language and Learning, 3(1), 104-115.

Tan, S. C., \& Tan, A. L. (2006). Conversational analysis as an analytical tool for face-to-face and online conversations. Educational Media International, 43(4), 347-361. http://dx.doi.org/10.1080/0952398060092 6374

Thai Library Integrated System. (2014). Digital Collection Working Group. Retrieved July 25, 2014, from http://www.thailis.or.th/tdc/

Trudgill, P. (1983). Sociolinguistics. An introduction to language and society. Penguin Books.

Ussuma, R., \& Singwongsuwat, K. (2014). Conversation proficiency assessment: A comparative study of two-party peer interaction and interview interaction implemented with Thai EFL learners. International Journal of Language Studies, 8(4), 95-106.

Van Lier, L. (1988a). The classroom and the language learner. New York: Longman.

Wanchai, N. (2012). Difficulties encountered in implementing a communicative curriculum: EFL Teachers' Perspectives. Retrieved July 15, 2014, from http://www.culi.chula.ac.th/Research/e-Journal/2012/Final\%20 RA\%20Difficulties\%20Encountered\%20in\%20Implementing\%20a\%20Communicative\%20Curriculum.pdf

Wiriyachitra, A. (2002). English language teaching and learning in Thailand in this decade. Thai TESOL Focus, 15(1), 4-9.

Wong, J., \& Waring, H. Z. (2010). Conversation Analysis and second language pedagogy. New York. Routledge. Taylor \& Francis Group. New York and London.

$\mathrm{Wu}, \mathrm{Y}$. (2013). Conversation Analysis. A discourse approach to teaching oral English skills. International Education Studies, 6(5), 87-91. http://dx.doi.org/105539/ies.v6n5p87

Young, R. (1999). Sociolinguistic approaches to SLA. Annual Review of Applied Linguistics, 19, 105-132.

\section{Copyrights}

Copyright for this article is retained by the author(s), with first publication rights granted to the journal.

This is an open-access article distributed under the terms and conditions of the Creative Commons Attribution license (http://creativecommons.org/licenses/by/3.0/). 